\title{
Design, synthesis, and biological evaluation of the novel glycyrrhetinic acid-cinnamoyl hybrids as anti-tumor agents
}

Wenbo Guo ${ }^{1+}$, Mengmeng Yan ${ }^{1 \dagger}$, Bing Xu', Fuhao Chu', Wei Wang ${ }^{1}$, Chenze Zhang ${ }^{1}$, Xiaohui Jia', Yaotian Han', Hongjun Xiang ${ }^{1}$, Yuzhong Zhang ${ }^{2}$, Penglong Wang ${ }^{1 *}$ and Haimin Lei ${ }^{1^{*}}$

\begin{abstract}
Background: Glycyrrhetinic acid (GA) derivatives had shown not only cytotoxicity but also could trigger apoptosis in various human cancer cell lines. Moreover, cinnamic acid (CA) and its phenolic analogues as potent antitumor agents were employed in the design of anti-tumor drugs. To further improve the anti-tumor activity of GA and CA derivatives, a series of novel compounds were designed and synthesized using GA and CA derivatives fragments.

Results: The result showed that all the novel glycyrrhetinic acid-cinnamoyl (GA-CA) hybrids presented higher antitumor activity on the tumor cell lines of HepG2, HT-29, Hela and lower cytotoxicity on three non-tumor cells lines MDCK, HY926, $\mathrm{H} 9 \mathrm{C} 2$ than the parent compounds $\left(\mathrm{IC}_{50}>50 \mu \mathrm{M}\right)$. It was worth noting that $\mathbf{8 a}$ had a superior cytotoxicity effect on Hela cells $\left(I C_{50}=8.54 \mu \mathrm{M}\right)$ than on other cancer cell lines $\left(I C_{50}>15 \mu \mathrm{M}\right)$. And it also indicated that $8 \mathbf{a}$ showed lower cytotoxicity $\left(\mathrm{IC}_{50}>27 \mu \mathrm{M}\right)$ towards MDCK, HY926 and H9C2 cells than cisplatin (DDP, $\left.\mathrm{IC}_{50}<10 \mu \mathrm{M}\right)$. Moreover, according to the acute toxicity, it could be indicated that the $L D_{50}$ of $\mathbf{8 a}$ exceeded $3.0 \mathrm{~g} / \mathrm{kg}$ by oral administration in mice. The further research using Giemsa, H33342 staining, flow cytometric analysis and caspase-3 assay showed that $\mathbf{8 a}$ could cause Hela cell damage, nuclei lysis and apoptosis. In addition, the structure-activity relationships of these hybrids were briefly discussed.

Conclusions: Compared with GA, target compounds demonstrated better anti-tumor activity, among which 8a was the most active one. What's more, structure-activity relationship analysis also revealed that hybrids with trans olefinic bond group show higher antitumor activity than those without olefinic bond, such as $\mathbf{1 a}>\mathbf{1} \mathbf{b}, \mathbf{6} \mathbf{a}>\mathbf{2} \mathbf{b}, \mathbf{8} \mathbf{a}>\mathbf{3 b}$,

$\mathbf{9 a}>\mathbf{4 b}$. In addition, it was found that the methoxy substituent might enhance selectivity of GA-CA hybrids towards regular non-cancerous cells MDCK, HY926 and H9C2, such as $\mathbf{4 a}, \mathbf{6 a}, \mathbf{7 a}, \mathbf{8 a}$. However, there might be less relationship between the cytotoxicity and the quantity, position of methoxy moiety. Hence, it is urgent need to synthesize efficient, low toxicity and multi-target anti-tumor compounds based on the structure combination principle.
\end{abstract}

Keywords: Glycyrrhetinic acid, Cinnamic acid, Synthesis, Biological evaluation, Anti-tumor, Combination principle

\section{Background}

In the process of drug discovery and development, natural products play a highly significant role $[1,2]$. A series of pentacyclic triterpenoids were proved to have potent antitumor activity [3-6]. Structural modification of bioactive

\footnotetext{
*Correspondence: wpl581@126.com; leihaimin@126.com

${ }^{\dagger}$ Wenbo Guo and Mengmeng Yan contributed equally to this work

${ }^{1}$ School of Chinese Pharmacy, Beijing University of Chinese Medicine, No.6 Wangjing Middle Ring South Road, Beijing, Chaoyang District, China Full list of author information is available at the end of the article
}

natural products according to combination principle was an important approach in search for new lead compounds [7-9]. Based on this principle, previous studies in our laboratory had already obtained a series of novel antitumor compounds with promising cytotoxicity [10-12]. Given the potent cytotoxicity and apoptosis-inducing activity of the natural pentacyclic triterpenoid GA, it is becoming a valuable lead compound in the design of anti-tumor drug [13]. It also had been reported that GA possessed selective toxicity to varieties of tumor cells $[14,15]$. The previous 
researches showed the introduction of ester-joined groups at 3-OH of GA could enhance the antitumor effect [16, 17]. Meanwhile, CA and its phenolic analogues were also employed as the active scaffold in the design of anti-tumor drugs for their potent cytotoxicity [13, 18-21]. Moreover, CA moiety could induce selective cytotoxicity in developing anti-tumor agents [21]. To further improve the antitumor effect of GA and CA derivatives and find a series of efficient, low toxicity, multi-target GA-CA hybrids, we integrated the GA and CA derivatives fragments into one molecule via an ester bond based on structural combination principle.

\section{Results and discussion Chemistry}

All the designed hybrids were synthesized according to Scheme 1. The coupling reactions between GA and the corresponding $\mathrm{CA}$ derivatives were performed using dimethylaminopyridine (DMAP) and dicyclohexylcarbodiimide (DCC) as the catalyst in anhydrous dichloromethane (DCM), to afford glycyrrhetinic acid hybrids 1a-9a, as shown in Scheme 1. Subsequently, compounds 1a, 6a, 8a, 9a were further hydrogenated by $\mathrm{Pd} / \mathrm{C}$ to obtain the target compounds $\mathbf{1 b}-\mathbf{4 b}$. The structures of all target compounds (Tables 1,2 ) were determined by ${ }^{1} \mathrm{H}-$ NMR, ${ }^{13} \mathrm{C}-\mathrm{NMR}$ and mass spectrometer (ESI-MS).

\section{Biological activity}

\section{Cytotoxicity assay}

As shown in Table 3, all the synthesized compounds were tested for their cytotoxicity on three tumor cell lines (HepG2, HT-29, and Hela) and three non-tumor cell lines (MDCK HY926 and H9C2) using the standard MTT assay and $\mathrm{IC}_{50}$ values for different cell lines were outlined.

After combination, most of the synthesized compounds showed improved cytotoxicity compared to GA. Among them, compound 8a demonstrated better cytotoxicity $\left(\mathrm{IC}_{50}=8.54 \mu \mathrm{M}\right)$ against Hela. Structure-activity relationship analysis among 1a, 6a, 8a, 9a, 1b-4b also
Table 1 The structures of glycyrrhetinic acid hybrids 1a-9a

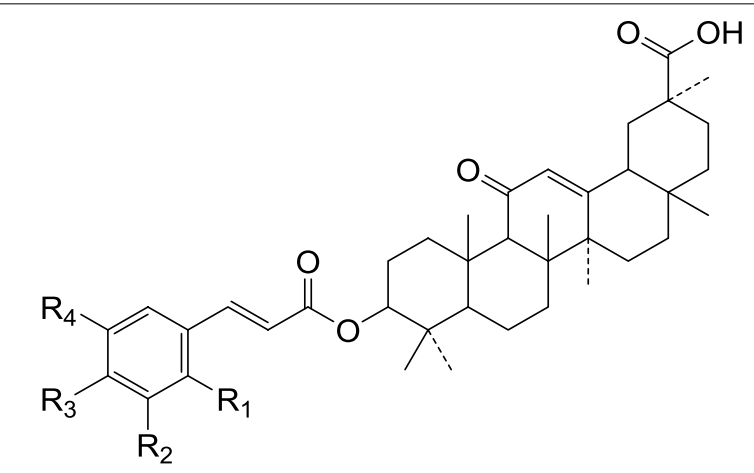

\begin{tabular}{lllll}
\hline No. & $\mathbf{R}_{\mathbf{1}}$ & $\mathbf{R}_{\mathbf{2}}$ & $\mathbf{R}_{\mathbf{3}}$ & $\mathbf{R}_{\mathbf{4}}$ \\
\hline $1 \mathrm{a}$ & $\mathrm{H}$ & $\mathrm{H}$ & $\mathrm{H}$ & $\mathrm{H}$ \\
$2 \mathrm{a}$ & $\mathrm{H}$ & $\mathrm{H}$ & $\mathrm{CH}_{3}$ & $\mathrm{H}$ \\
$3 \mathrm{a}$ & $\mathrm{OCH}_{3}$ & $\mathrm{H}$ & $\mathrm{H}$ & $\mathrm{H}$ \\
$4 \mathrm{a}$ & $\mathrm{H}$ & $\mathrm{OCH}_{3}$ & $\mathrm{H}$ & $\mathrm{H}$ \\
$5 \mathrm{a}$ & $\mathrm{H}$ & $\mathrm{H}$ & $\mathrm{OCH}_{3}$ & $\mathrm{H}$ \\
$6 \mathrm{a}$ & $\mathrm{OCH}_{3}$ & $\mathrm{OCH}_{3}$ & $\mathrm{H}$ & $\mathrm{H}$ \\
$7 \mathrm{a}$ & $\mathrm{OCH}_{3}$ & $\mathrm{H}$ & $\mathrm{H}$ & $\mathrm{OCH}_{3}$ \\
$8 \mathrm{a}$ & $\mathrm{OCH}_{3}$ & $\mathrm{OCH}_{3}$ & $\mathrm{OCH}_{3}$ & $\mathrm{H}$ \\
$9 \mathrm{a}$ & $\mathrm{H}$ & $\mathrm{OCH}_{3}$ & $\mathrm{OCH}_{3}$ & $\mathrm{OCH}_{3}$ \\
\hline
\end{tabular}

revealed that compounds with trans olefinic bond group seemed to more active than those without olefinic bond, such as $1 \mathbf{a}>1 \mathbf{b}, \mathbf{6 a}>2 \mathbf{b}, \mathbf{8 a}>3 \mathbf{b}, \mathbf{9 a}>4 \mathbf{b}$. This structure-activity relationship analysis was in agreement with our previous study in designing neuroprotective agents [9]. Compared to $1 \mathrm{a}\left(\mathrm{IC}_{50}<25 \mu \mathrm{M}\right)$, it was found that the methoxy substituent might enhance cytotoxicity selectivity of GA-CA hybrids towards tumor cell lines, such as $4 \mathbf{a}, 6 \mathbf{a}, 7 \mathbf{a}, 8 \mathbf{a}$. This was in accordance with the previous study that dihydroartemisinin-cinnamic acid ester hybrids with methoxy moiety displayed highly selective cytotoxicity against the human lung carcinoma A549 cells, although it showed low cytotoxicity on non-tumor

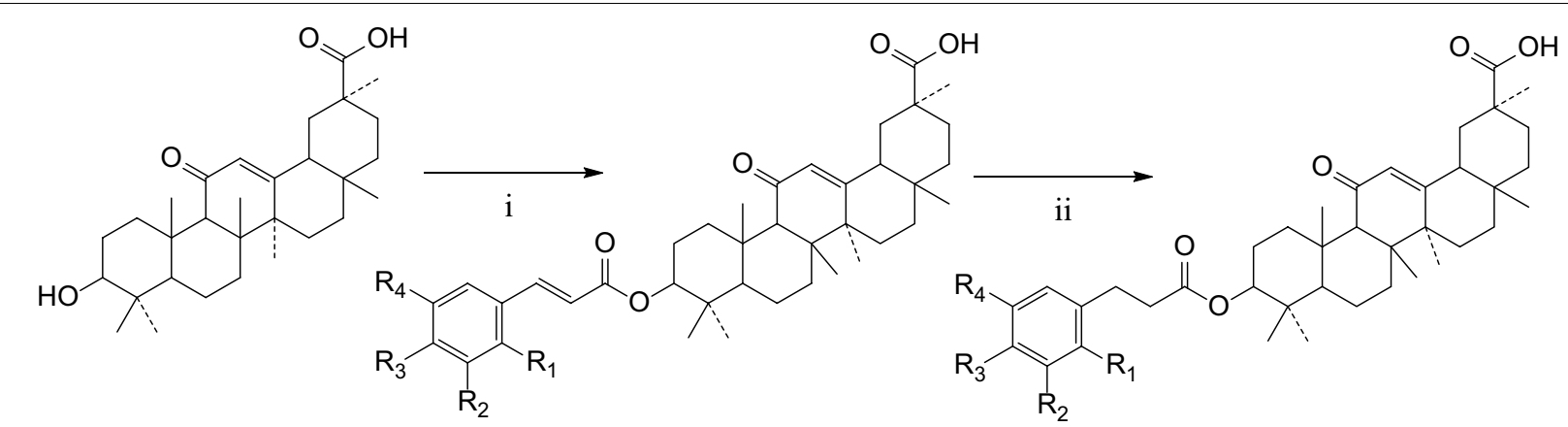

Scheme 1 Reagents and conditions: (i) anhydrous $\mathrm{CH}_{2} \mathrm{Cl}_{2}$, DMAP/DCC, $24 \mathrm{~h}$; (ii) THF, $\mathrm{Pd} / \mathrm{C}, \mathrm{H}_{2}, 2 \mathrm{~h}$ 
Table 2 The structures of glycyrrhetinic acid hybrids $\mathbf{1 b}-\mathbf{4 b}$

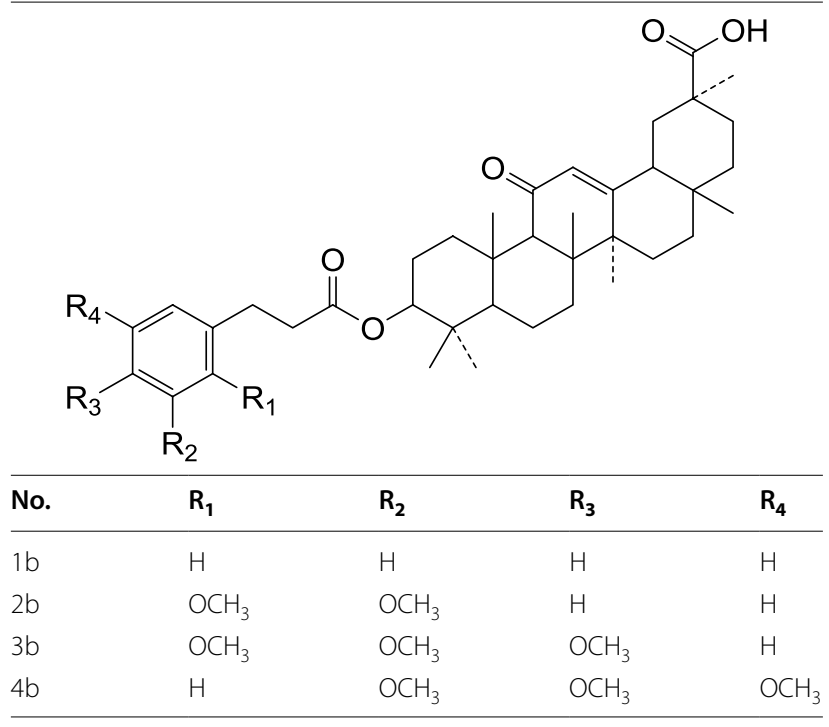

hepatic L-02 cells [21]. However, there might be less relationship between cytotoxicity and the quantity, position of methoxy moiety. These findings may provide a new framework for the design of new GA hybrids as antitumor drugs.

\section{Cytotoxicity selectivity}

Based on the above evidence, 8a showed selective cytotoxicity towards Hela cell lines. The different inhibition activity of $\mathbf{8 a}$ for Hela, HY926, MDCK and H9C2 cells are shown in Fig. 1 detailedly. Taken together, the results demonstrated that $\mathbf{8 a}$ displayed not only selective cytotoxicity on Hela cell lines, but also a concentrationdependent manner.

From the obtained results, we can see the inhibition rate of $8 \mathbf{a}$ at $12.5 \mu \mathrm{M}$ against MDCK, HY926, H9C2 and Hela were $38.56,20.20,3.56$ and $59.20 \%$. Hence, in a certain degree, compound $\mathbf{8 a}$ might have cytotoxicity selectively towards Hela.

\section{Acute toxicity}

As the above results showed, 8a had a selective cytotoxicity against tumor cells. In order to test its safety, the acute toxicity of $\mathbf{8} \mathbf{a}$ was evaluated by gavage. During the 2 weeks after oral administration of the maximum tolerated dose $(3 \mathrm{~g} / \mathrm{kg})$, no signs of toxicity or deaths were observed.

\section{Giemsa staining on Hela cells}

To confirm whether the apoptotic morphological changes could be associated with $\mathbf{8 a}$, Hela cells were treated with various concentrations of $\mathbf{8 a}$ for $72 \mathrm{~h}$ and then used Giemsa staining. The morphology changes were observed and photographed under inverted phase-contrast microscope at a magnification of $200 \times$. With the increase of drug concentration, the process of cell loss, nuclei lysis, chromatin condensation and cytoplasmic shrinkage were aggravated (Fig. 2).

\section{H33342 staining on Hela cells}

To confirm whether the characteristic nuclear changes could be associated with $\mathbf{8 a}$, Hela cells were treated

Table 3 Anti-proliferative effects of glycyrrhetinic acid hybrids

\begin{tabular}{|c|c|c|c|c|c|c|}
\hline \multirow[t]{2}{*}{ Compound } & \multicolumn{6}{|l|}{$I C_{50}(\mu M)^{a}$} \\
\hline & Hela & HepG2 & HT-29 & MDCK & HY926 & $\mathrm{H} 9 \mathrm{C} 2$ \\
\hline $1 \mathrm{a}$ & $23.67 \pm 2.98$ & $24.40 \pm 1.39$ & $22.34 \pm 1.75$ & $22.63 \pm 1.38$ & $28.93 \pm 1.85$ & $46.13 \pm 2.01$ \\
\hline $2 a$ & $14.19 \pm 1.10$ & $22.08 \pm 1.18$ & $21.72 \pm 1.81$ & $37.95 \pm 1.81$ & $27.63 \pm 1.84$ & $>50$ \\
\hline $3 a$ & $24.56 \pm 1.72$ & $31.99 \pm 1.90$ & $22.16 \pm 2.34$ & $22.93 \pm 2.43$ & $>50$ & $>50$ \\
\hline $4 a$ & $17.53 \pm 1.52$ & $12.67 \pm 1.10$ & $14.88 \pm 1.80$ & $22.24 \pm 2.56$ & $31.01 \pm 1.87$ & $>50$ \\
\hline $5 a$ & $23.38 \pm 1.38$ & $31.15 \pm 1.34$ & $32.99 \pm 1.92$ & $21.67 \pm 1.01$ & $>50$ & $36.14 \pm 1.92$ \\
\hline $6 a$ & $22.48 \pm 2.08$ & $24.36 \pm 1.44$ & $24.39 \pm 1.76$ & $33.67 \pm 1.40$ & $24.99 \pm 1.38$ & $>50$ \\
\hline $7 a$ & $28.01 \pm 1.63$ & $25.41 \pm 1.97$ & $26.41 \pm 1.96$ & $>50$ & $45.07 \pm 2.25$ & $>50$ \\
\hline $8 a$ & $8.54 \pm 1.44$ & $21.47 \pm 1.50$ & $15.02 \pm 1.26$ & $31.84 \pm 2.79$ & $27.73 \pm 1.39$ & $>50$ \\
\hline $9 a$ & $30.67 \pm 1.89$ & $21.88 \pm 1.41$ & $25.52 \pm 1.29$ & $27.72 \pm 1.08$ & $30.79 \pm 1.37$ & $47.43 \pm 1.07$ \\
\hline $1 b$ & $26.92 \pm 1.74$ & $32.29 \pm 1.00$ & $28.63 \pm 2.99$ & $33.33 \pm 2.98$ & $33.65 \pm 3.09$ & $>50$ \\
\hline $2 b$ & $23.13 \pm 2.33$ & $33.08 \pm 2.09$ & $29.34 \pm 2.22$ & $41.30 \pm 1.48$ & $>50$ & $45.75 \pm 1.80$ \\
\hline $3 \mathbf{b}$ & $22.54 \pm 2.16$ & $27.31 \pm 1.95$ & $26.21 \pm 1.24$ & $>30$ & $38.46 \pm 2.02$ & $>50$ \\
\hline $4 b$ & $28.69 \pm 1.68$ & $22.38 \pm 1.29$ & $22.35 \pm 1.2$ & $>30$ & $>50$ & $>50$ \\
\hline GA & $>50$ & $>50$ & $>50$ & $>100$ & $>100$ & $>100$ \\
\hline DPP & $3.76 \pm 0.38$ & $4.57 \pm 0.85$ & $5.28 \pm 0.74$ & $9.97 \pm 1.12$ & $5.12 \pm 0.71$ & $5.31 \pm 0.26$ \\
\hline
\end{tabular}

a IC50 values were calculated using GraphPad Prism 5.01. Data were shown as mean \pm SD $(n=3)$ from three independent experiments 


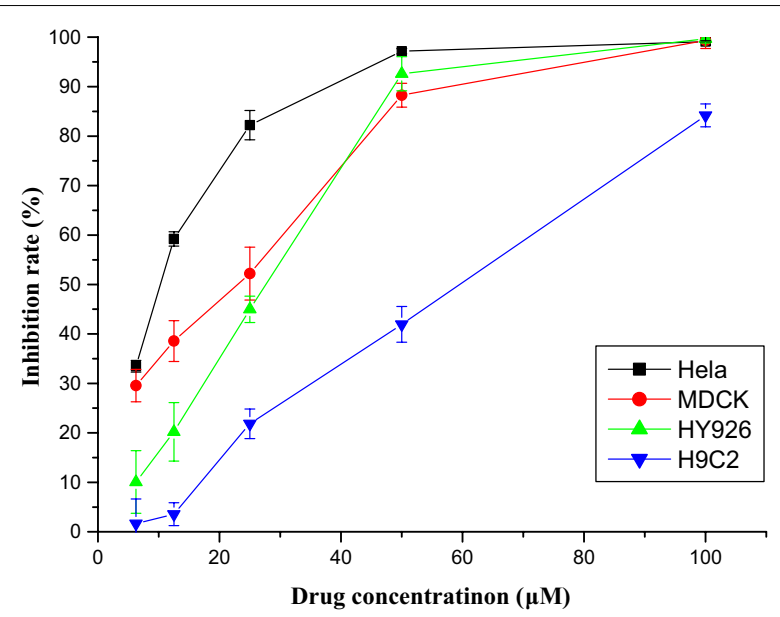

Fig. 1 The different inhibition activity of $\mathbf{8 a}$ for Hela, HY926, MDCK and $\mathrm{H} 9 \mathrm{C} 2$ cells

with various concentrations of $\mathbf{8 a}$ for $72 \mathrm{~h}$ and then used H33342 staining. The morphology changes were observed and photographed under inverted phase-contrast microscope at a magnification of $200 \times$. With the increase of drug concentration, the nuclear fragmentation, the cytoplasmic shrinkage, and the shape of apoptotic cells became irregular (Fig. 3).

\section{Annexin V-FITC/propidium iodide (PI) assay}

The effects of 8a on apoptosis in Hela cells were further determined by flow cytometric analysis. Cells were treated with 8a at three concentrations of 5, 10, $20 \mu \mathrm{M}$ and then stained with both annexin V-FITC and PI. The flow cytometry observed four quadrant images: the Q1 area represented necrotic cells, the Q2 area represented late apoptotic cells, the Q3 area represented intact cells and the Q4 area represented the early apoptotic cells. The results were shown in Fig. 4. The apoptosis ratios of $\mathbf{8 a}$ were found from $15.7 \%(5 \mu \mathrm{M})$ to $27.7 \%(10 \mu \mathrm{M})$ and $60 \%$ $(20 \mu \mathrm{M})$ which increased gradually in a concentration manner, respectively, while that of the control was $7.5 \%$. It was indicated that $\mathbf{8 a}$ was able to significantly induce Hela cells apoptosis. This was in accordance with previous reports that GA and CA hybrids could induce cancer cell apoptosis $[5,20]$.
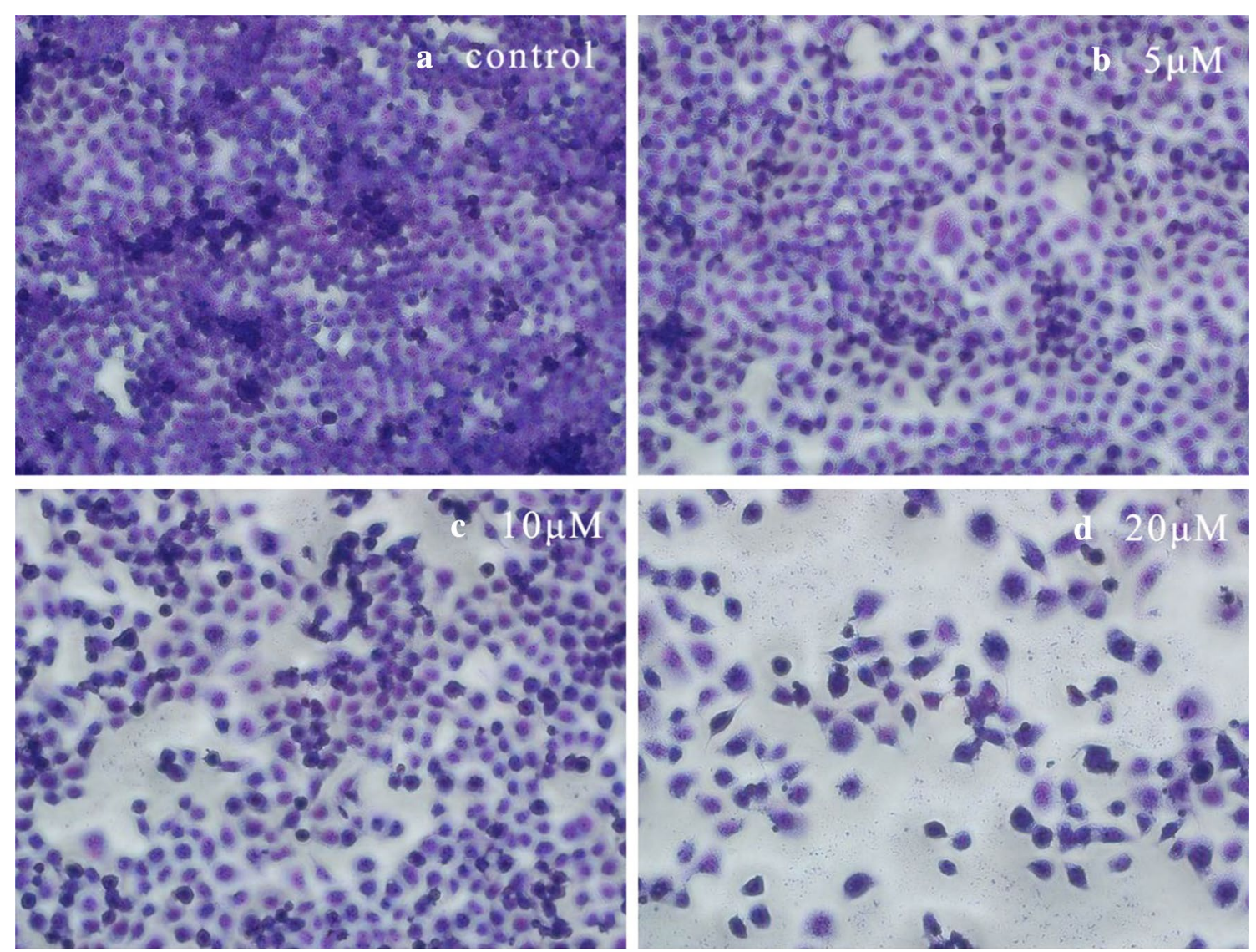

Fig. 2 Morphological changes observation of Hela cells by Giemsa staining ( $\times 200)$ : a control group without $8 \mathbf{8}$; b $5 \mu \mathrm{M}$ of $\mathbf{8 a}$; $\mathbf{c} 10 \mu \mathrm{M}$ of $\mathbf{8 a}$; d $20 \mu \mathrm{M}$ of $\mathbf{8 a}$. The cell morphology was observed and photographed under inverted phase-contrast microscope after Giemsa staining 

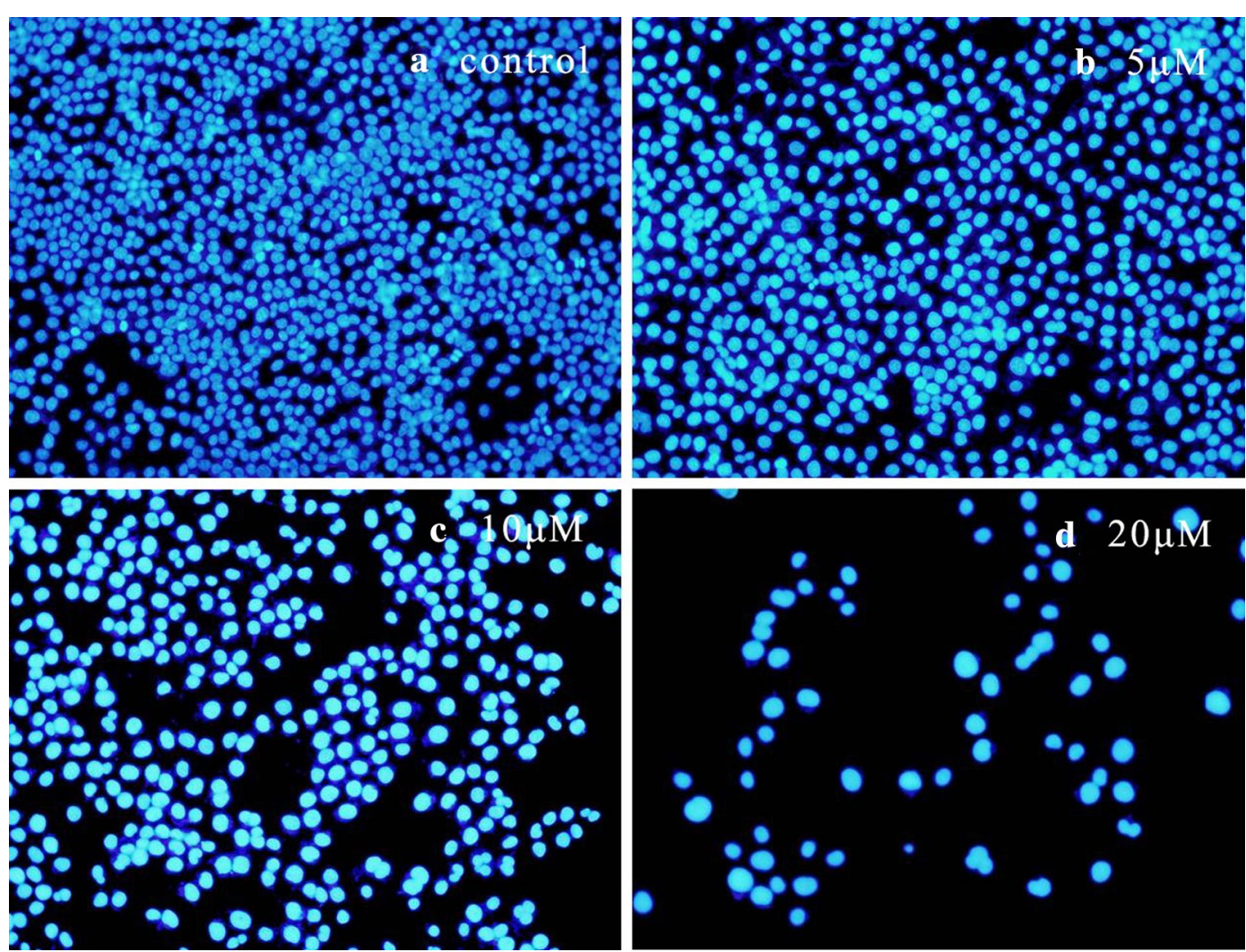

Fig. 3 Morphological changes observation of Hela cells by H33342 staining ( $\times 200)$ : a control group without $8 \mathbf{a} ; \mathbf{b} 5 \mu \mathrm{M}$ of $\mathbf{8 a}$; $\mathbf{c} 10 \mu \mathrm{M}$ of $\mathbf{8 a}$; d $20 \mu \mathrm{M}$ of $\mathbf{8 a}$. The cell morphology was observed and photographed under inverted phase-contrast microscope after H33342 staining

\section{Caspase-3 assay}

From the results of flow cytometry analysis, it could be clarified that 8a was able to significantly induce Hela cells apoptosis. What's more, caspase- 3 plays a crucial role in the process of apoptosis induced. The method of measuring the levels of $\rho$-nitroanilide cleaved from the substrate N-Ac-DEVD-pNA was followed to determine the caspase-3 activity. As shown in Fig. 5, caspase-3 activities in Hela cells were enhanced in a concentration-dependent manner after the cells were exposed to $\mathbf{8 a}$, from which it could be implicated that caspase- 3 was activated by $\mathbf{8 a}$ to promote the apoptosis of the cells.

\section{Conclusions}

Studies on synthetic glycyrrhetinic acid derivatives and their bioactivities drew considerable attention in the past several years. Our experimental findings suggested that all GA-CA hybrids showed better cytotoxicity than the parent materials in tested cancer cells. Among the active compounds, 8a presented a superior cytotoxicity effect on Hela cells $\left(\mathrm{IC}_{50}=8.54 \mu \mathrm{M}\right)$ than on other cancer cell lines and exhibited lower cytotoxicity towards three non-tumor cells lines (MDCK, HY926, H9C2) than DDP. Furthermore, structure-activity relationship analysis revealed that hybrids with trans olefinic bond group were more active than those without olefinic bond, and we found that the methoxy substituent could enhance cytotoxicity selectivity of GA-CA hybrids. In order to further confirm our conclusion, we combined Giemsa, H33342 staining, flow cytometric analysis and caspase-3 assay indicated that $\mathbf{8 a}$ could induce Hela cells damage, nuclei lysis, block intercellular contact and apoptosis. From these results, it obviously suggests that synthesis compounds based on the structure combination principle to discover more efficient and low toxicity anti-tumor compounds is of great research value.

\section{Methods \\ Chemistry information}

GA was purchased from State Uni-Bio Technology Co., Ltd., Baoji, China. Cinnamic acid and its derivatives were obtained from Aladdin Bio-Chem Technology Co., Ltd., China and Alfa Aesar Chemical Co., Ltd., Tianjin, China. The purity of all the materials, including GA, cinnamic 

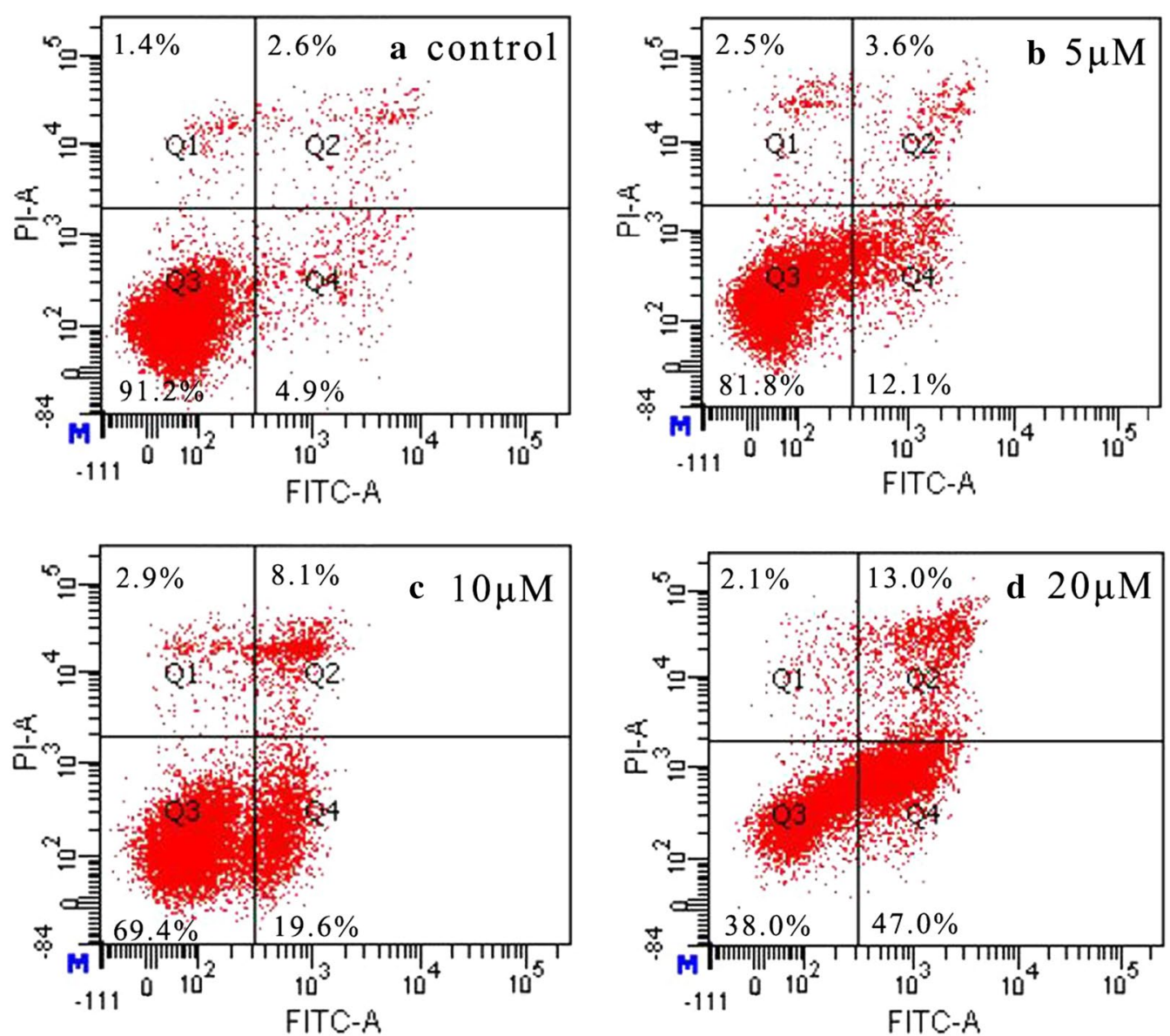

Fig. 4 Apoptosis analysis by FCM using AnnexinV-FITC/PI staining on the Hela cells treated by $\mathbf{8 a}$; a control group without $\mathbf{8 a} ; \mathbf{b} 5 \mu \mathrm{M}$ of $\mathbf{8 a} ; \mathbf{c}$ $10 \mu \mathrm{M}$ of $\mathbf{8 a}$; d $20 \mu \mathrm{M}$ of $\mathbf{8 a}$

acid and its derivatives are more than $98 \%$ by commercial purchase. Reagents of analytical reagent grade were provided by Beijing Chemical Plant. All reagents and chemicals were used as received without further purification unless specific stated. The aluminum sheets covered silica gel (Qingdao Haiyang Chemical Co., Qingdao, China) were used to monitor the reactions.

The melting points of purified products were obtained on an X-5 micro melting- point apparatus (Beijing Tech Instrument Co., Ltd., Beijing, China). ${ }^{1} \mathrm{H}-\mathrm{NMR}$ and ${ }^{13} \mathrm{C}$ NMR assays were recorded on a BRUKER AVANCE 500 or 400 NMR spectrometer (Fällanden, Switzerland). ESI-MS were recorded on a Thermo Scientific TM LTQ Orbitrap XL hybrid FTMS instrument (Thermo Technologies, New York, NY, USA). The final products were purified on 200-300 mesh silica gel. Cellular morphologies were observed using an inverted fluorescence microscope (Olympus IX71, Tokyo, Japan). On the last step reaction the yields can be calculated.
General procedure for the preparation of glycyrrhetinic acidcinnamic acid hybrids $1 a-9 a$

The corresponding cinnamic acid derivatives $(6.0 \mathrm{mmol})$ and DMAP $(0.6 \mathrm{mmol})$ were mixed in $50 \mathrm{~mL}$ dry DCM, as well as DCC. After dissolution, the glycyrrhetinic acid ( $3.5 \mathrm{mmol}$ ) was added. The mixture was stirred under nitrogen atmosphere at room temperature for $24 \mathrm{~h}$. Afterwards, the solution was washed with brine, dried over sodium sulfate, filtered and concentrated. To yield pure product, the crude product was purified by flash chromatography (dichloromethane: methanol $=200: 1$ ).

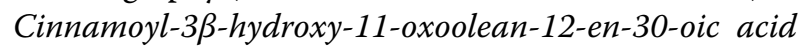
(1a). White solid, yield: $45.0 \%$, m.p.: $315.2-318.8^{\circ} \mathrm{C} .{ }^{1} \mathrm{H}-$ NMR (500 MHz, $\mathrm{CDCl}_{3}$ ) (ppm): 0.85, 0.93, 0.97, 1.15, $1.20,1.24,1.39$ (s, each, $\left.3 \mathrm{H}, 7 \times-\mathrm{CH}_{3}\right), 4.67(\mathrm{~m}, 1 \mathrm{H})$, $5.73(\mathrm{~s}, 1 \mathrm{H},=\mathrm{CH}-), 6.45(\mathrm{~d}, J=16.0 \mathrm{~Hz}, 1 \mathrm{H},-\mathrm{CH}=)$, 7.35-7.40 (m, 3H, Ar-H), 7.53-7.54 (m, 2H, Ar-H), 7.67 $(\mathrm{d}, J=16.0 \mathrm{~Hz}, 1 \mathrm{H},-\mathrm{CH}=), 1.00-3.00(22 \mathrm{H}$, methyland methylene- of triterpenoid structure). ${ }^{13} \mathrm{C}-\mathrm{NMR}$ 


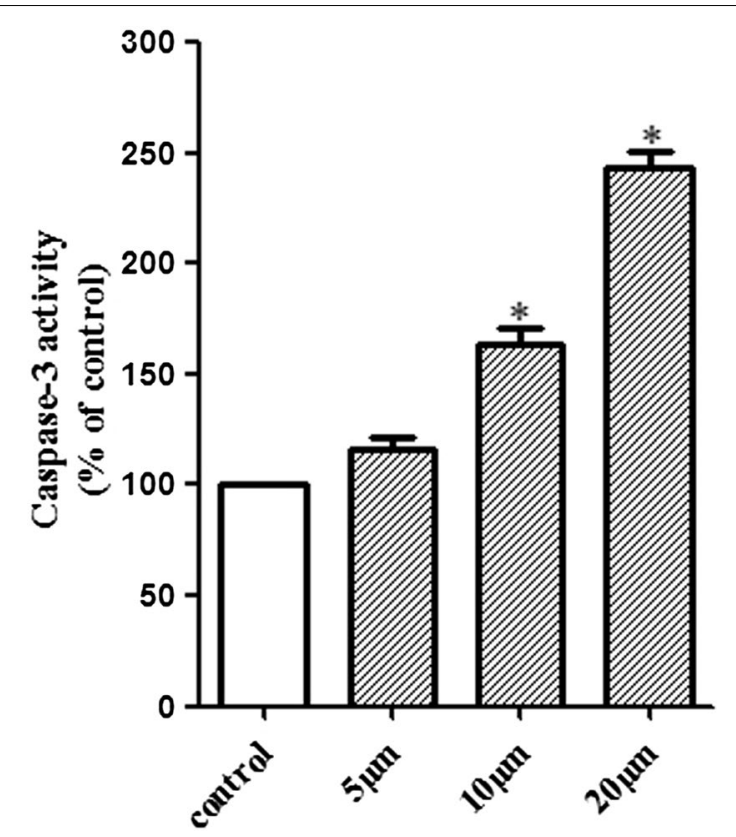

Fig. 5 Caspase-3 activity of $\mathbf{8 a}$ on Hela cells. Values of caspase-3 activity are reported as mean $\pm S D(n=3)$. ${ }^{*}$ Compared with control group, $P<0.05$

$\left(125 \mathrm{MHz}, \mathrm{CDCl}_{3}\right)(\mathrm{ppm}): 16.6,17.0,17.5,18.8,23.5,23.8$, 26.6, 26.6, 28.3, 28.6, 28.7, 31.1, 32.0, 32.9, 37.1, 37.9, 38.5, 39.0, 41.0, 43.4, 43.9, 45.6, 48.4, 55.2, 61.9, 80.8, 119.0, 128.2, 128.6, 129.0, 130.3, 134.7, 144.5, 167.0, 169.6, 181.6 $(-\mathrm{COOH}), 200.5(-\mathrm{C}=\mathrm{O})$. MS (ESI) m/z: $599[\mathrm{M}-\mathrm{H}]^{-}$, calcd. for $\mathrm{C}_{39} \mathrm{H}_{52} \mathrm{O}_{5} 600$.

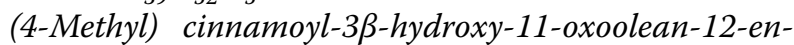
30-oic acid (2a). White solid, yield: 47.3\%, m.p.: 316.6$318.1^{\circ} \mathrm{C} .{ }^{1} \mathrm{H}-\mathrm{NMR}\left(500 \mathrm{MHz}, \mathrm{CDCl}_{3}\right.$ ) (ppm): 0.84, 0.92, 0.96, 1.14, 1.19, 1.23, 1.38 (s, each, $\left.3 \mathrm{H}, 7 \times-\mathrm{CH}_{3}\right), 2.37$ $\left(\mathrm{s}, 3 \mathrm{H},-\mathrm{CH}_{3}\right), 4.66(\mathrm{~m}, 1 \mathrm{H}), 5.72(\mathrm{~s}, 1 \mathrm{H},=\mathrm{CH}-), 6.40(\mathrm{~d}$, $J=16.0 \mathrm{~Hz}, 1 \mathrm{H},-\mathrm{CH}=), 7.18(\mathrm{~d}, J=8.0 \mathrm{~Hz}, 2 \mathrm{H}, \mathrm{Ar}-\mathrm{H})$, $7.43(\mathrm{~d}, J=8.0 \mathrm{~Hz}, 2 \mathrm{H}, \mathrm{Ar}-\mathrm{H}), 7.64(\mathrm{~d}, J=16.0 \mathrm{~Hz}, 1 \mathrm{H}$, $-\mathrm{CH}=), 1.00-3.00(22 \mathrm{H}$, methyl- and methylene- of triterpenoid structure). ${ }^{13} \mathrm{C}-\mathrm{NMR}\left(125 \mathrm{MHz}, \mathrm{CDCl}_{3}\right)$ (ppm): 16.6, 17.0, 17.5, 18.8, 21.6, 23.5, 23.8, 26.5, 26.6, 28.2, 28.6, 28.7, 31.0, 32.0, 32.9, 37.1, 37.9, 38.4, 38.9, 41.0, 43.4, $43.9,45.6,48.4,55.2,61.9,80.7,117.8,128.2$, 128.6, 129.7, 131.9, 140.7, 144.5, 167.2, 169.6, 181.7 (-COOH), 200.5 $(-\mathrm{C}=\mathrm{O})$. MS (ESI) m/z: $613[\mathrm{M}-\mathrm{H}]^{-}$, calcd. for $\mathrm{C}_{40} \mathrm{H}_{54} \mathrm{O}_{5}$ 614.

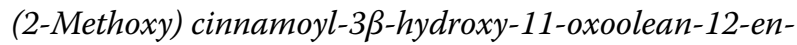
30-oic acid (3a). White solid, yield: 45.7\%, m.p.: 317.0$319.2{ }^{\circ} \mathrm{C} .{ }^{1} \mathrm{H}-\mathrm{NMR}\left(500 \mathrm{MHz}, \mathrm{CDCl}_{3}\right.$ ) (ppm): 0.84, 0.92, $0.96,1.14,1.19,1.23,1.38$ (s, each, $\left.3 \mathrm{H}, 7 \times-\mathrm{CH}_{3}\right), 3.88$ (s, $\left.3 \mathrm{H},-\mathrm{OCH}_{3}\right), 4.66(\mathrm{~m}, 1 \mathrm{H}), 5.72(\mathrm{~s}, 1 \mathrm{H},=\mathrm{CH}-), 6.52(\mathrm{~d}$, $J=16.0 \mathrm{~Hz}, 1 \mathrm{H},-\mathrm{CH}=), 6.91(\mathrm{~d}, J=8.0 \mathrm{~Hz}, 1 \mathrm{H}, \mathrm{Ar}-\mathrm{H})$, $6.95(\mathrm{t}, J=7.5 \mathrm{~Hz}, 1 \mathrm{H}, \mathrm{Ar}-\mathrm{H}), 7.35(\mathrm{~m}, 1 \mathrm{H}, \mathrm{Ar}-\mathrm{H}), 7.51$ (m, 1H, Ar-H), 7.98 (d, $J=16.0 \mathrm{~Hz}, 1 \mathrm{H},-\mathrm{CH}=)$ ), 1.00$3.00(22 \mathrm{H}$, methyl- and methylene- of triterpenoid structure). ${ }^{13} \mathrm{C}-\mathrm{NMR}\left(125 \mathrm{MHz}, \mathrm{CDCl}_{3}\right)$ (ppm): 16.6, 17.0, 17.5, 18.8, 23.5, 23.8, 26.5, 26.6, 28.2, 28.6, 28.7, 31.0, 32.0, $32.8,37.1,37.8,38.4,38.9,40.9,43.3,43.9,45.6,48.4,55.1$, 55.6 (-OCH3), 61.8, 80.5, 111.2, 119.4, 120.8, 123.6, 128.5, 129.0, 131.5, 139.9, 158.4, 167.5, 169.7, 181.7 (-COOH), $200.6(-\mathrm{C}=\mathrm{O})$. MS (ESI) m/z: $629[\mathrm{M}-\mathrm{H}]^{-}$, calcd. for $\mathrm{C}_{40} \mathrm{H}_{54} \mathrm{O}_{6} 630$.

(3-Methoxy) cinnamoyl-3 $\beta$-hydroxy-11-oxoolean-12-en30-oic acid (4a). White solid, yield: $65.5 \%$, m.p.: 316.8$319.1{ }^{\circ} \mathrm{C},{ }^{1} \mathrm{H}-\mathrm{NMR}$ (400 MHz, $\mathrm{CDCl}_{3}$ ) (ppm): 0.84, 0.93, 0.97, 1.15, 1.20, 1.24, 1.39 (s, each, $\left.3 \mathrm{H}, 7 \times-\mathrm{CH}_{3}\right), 3.84$ $\left(\mathrm{s}, 3 \mathrm{H},-\mathrm{OCH}_{3}\right), 4.67(\mathrm{~m}, 1 \mathrm{H}), 5.72(\mathrm{~s}, 1 \mathrm{H},=\mathrm{CH}-), 6.43$ (d, $J=16.0 \mathrm{~Hz}, 1 \mathrm{H},-\mathrm{CH}=), 6.93(\mathrm{dd}, J=8.0,2.0 \mathrm{~Hz}$, $1 \mathrm{H}, \mathrm{Ar}-\mathrm{H}), 7.05$ (s, 1H, Ar-H), $7.13(\mathrm{~d}, J=8.0 \mathrm{~Hz}, 1 \mathrm{H}$, Ar-H), 7.28-7.32 (m, 1H, Ar-H), 7.63 (d, J=16.0 Hz, $1 \mathrm{H}$, $-\mathrm{CH}=), 1.00-3.00(22 \mathrm{H}$, methyl- and methylene- of triterpenoid structure). ${ }^{13} \mathrm{C}-\mathrm{NMR}\left(100 \mathrm{MHz}, \mathrm{CDCl}_{3}\right)$ (ppm): 16.6, 17.0, 17.6, 18.9, 23.5, 23.9, 26.6, 26.7, 28.3, 28.6, 28.7, $31.1,32.0,32.9,37.2,37.9,38.5,39.0,41.1,43.4,44.0,45.6$, $48.4,55.2,55.5\left(-\mathrm{OCH}_{3}\right), 61.9,80.9,113.0,116.3,119.3$, $120.9,128.7,130.0,136.1,144.4,160.1,166.9,169.5,181.4$ $(-\mathrm{COOH}), 200.4(-\mathrm{C}=\mathrm{O})$. MS $(\mathrm{ESI}) \mathrm{m} / \mathrm{z}: 629[\mathrm{M}-\mathrm{H}]^{-}$, calcd. for $\mathrm{C}_{40} \mathrm{H}_{54} \mathrm{O}_{6} 630$.

(4-Methoxy) cinnamoyl-3 $\beta$-hydroxy-11-oxoolean-12-en30-oic acid (5a). White solid, yield: 49.4\%, m.p.: 316.9$319.1{ }^{\circ} \mathrm{C}$. ${ }^{1} \mathrm{H}-\mathrm{NMR}\left(500 \mathrm{MHz}, \mathrm{CDCl}_{3}\right.$ ) (ppm): 0.84, 0.92, $0.95,1.14,1.19,1.23,1.38$ (s, each, $\left.3 \mathrm{H}, 7 \times-\mathrm{CH}_{3}\right), 3.83$ (s, $\left.3 \mathrm{H},-\mathrm{OCH}_{3}\right), 4.65(\mathrm{~m}, 1 \mathrm{H}), 5.72(\mathrm{~s}, 1 \mathrm{H},=\mathrm{CH}-), 6.32(\mathrm{~d}$, $J=16.0 \mathrm{~Hz}, 1 \mathrm{H},-\mathrm{CH}=), 6.90(\mathrm{~d}, J=8.5 \mathrm{~Hz}, 2 \mathrm{H}, \mathrm{Ar}-\mathrm{H})$, 7.48 (d, $J=8.5 \mathrm{~Hz}, 2 \mathrm{H}, \mathrm{Ar}-\mathrm{H}), 7.62$ (d, $J=16.0 \mathrm{~Hz}, 1 \mathrm{H}$, $-\mathrm{CH}=), 1.00-3.00(22 \mathrm{H}$, methyl- and methylene- of triterpenoid structure). ${ }^{13} \mathrm{C}-\mathrm{NMR}\left(125 \mathrm{MHz}, \mathrm{CDCl}_{3}\right)$ (ppm): 16.6, 17.0, 17.5, 18.8, 23.5, 23.8, 26.5, 26.6, 28.2, 28.6, 28.7, 31.0, 32.0, 32.8, 37.1, 37.8, 38.4, 38.9, 41.0, 43.3, 43.9, 45.6, $48.4,55.2,55.6\left(-\mathrm{OCH}_{3}\right), 61.8,80.5,114.4,116.4,127.4$, $128.6,129.8,144.1,161.4,167.3,170.0,181.6$ (-COOH), $200.6(-\mathrm{C}=\mathrm{O})$. MS (ESI) m/z: $631[\mathrm{M}+\mathrm{H}]^{+}$, calcd. for $\mathrm{C}_{40} \mathrm{H}_{54} \mathrm{O}_{6} 630$.

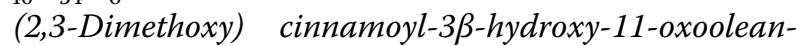
12-en-30-oic acid (6a). White solid, yield: 53.4\%, m.p.: 315.1-318.4 ${ }^{\circ} \mathrm{C}$. ${ }^{1} \mathrm{H}-\mathrm{NMR}\left(400 \mathrm{MHz}, \mathrm{CDCl}_{3}\right.$ ) (ppm): 0.84, $0.93,0.96,1.14,1.20,1.24,1.39$ (s, each, $3 \mathrm{H}, 7 \times-\mathrm{CH}_{3}$ ), $3.86\left(\mathrm{~s}, 3 \mathrm{H},-\mathrm{OCH}_{3}\right), 3.88\left(\mathrm{~s}, 3 \mathrm{H},-\mathrm{OCH}_{3}\right), 4.66(\mathrm{~m}, 1 \mathrm{H})$, $5.72(\mathrm{~s}, 1 \mathrm{H},=\mathrm{CH}-), 6.47(\mathrm{~d}, J=16.2 \mathrm{~Hz}, 1 \mathrm{H},-\mathrm{CH}=)$, $6.93(\mathrm{dd}, J=8.0,1.2 \mathrm{~Hz}, 1 \mathrm{H}, \mathrm{Ar}-\mathrm{H}), 7.05(\mathrm{t}, J=8.0 \mathrm{~Hz}$, $1 \mathrm{H}, \mathrm{Ar}-\mathrm{H}), 7.17$ (dd, $J=8.0,1.2 \mathrm{~Hz}, 1 \mathrm{H}, \mathrm{Ar}-\mathrm{H}), 8.00$ (d, $J=16.0 \mathrm{~Hz}, 1 \mathrm{H},-\mathrm{CH}=), 1.00-3.00$ (22H, methyland methylene- of triterpenoid structure). ${ }^{13} \mathrm{C}-\mathrm{NMR}$ $\left(100 \mathrm{MHz} \mathrm{CDCl}_{3}\right)$ (ppm): 16.6, 17.0, 17.6, 18.9, 23.6, 23.9, 26.6, 26.7, 28.3, 28.6, 28.7, 31.1, 32.0, 32.9, 37.2, 37.9, 38.5 , 39.0, 41.1, 43.4, 43.9, 45.7, 48.4, 55.3, $56.1\left(-\mathrm{OCH}_{3}\right)$, 
$61.5\left(-\mathrm{OCH}_{3}\right), 61.9,80.8,114.0,119.4,120.2,124.3,128.7$, $128.9,139.2,148.6,153.3,167.1,169.5,181.3$ (-COOH), $200.5(-\mathrm{C}=\mathrm{O})$. MS (ESI) m/z: $659[\mathrm{M}-\mathrm{H}]^{-}$, calcd. for $\mathrm{C}_{41} \mathrm{H}_{56} \mathrm{O}_{7} 660$.

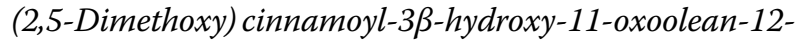
en-30-oic acid (7a). White solid, yield: 57.1\%, m.p.: 316.4$319.1{ }^{\circ} \mathrm{C}$. ${ }^{1} \mathrm{H}-\mathrm{NMR}\left(400 \mathrm{MHz}, \mathrm{CDCl}_{3}\right.$ ) (ppm): 0.85, 0.94, $0.98,1.16,1.21,1.25,1.40$ (s, each, $\left.3 \mathrm{H}, 7 \times-\mathrm{CH}_{3}\right), 3.80(\mathrm{~s}$, $\left.3 \mathrm{H},-\mathrm{OCH}_{3}\right), 3.85\left(\mathrm{~s}, 3 \mathrm{H},-\mathrm{OCH}_{3}\right), 4.68(\mathrm{~m}, 1 \mathrm{H}), 5.72(\mathrm{~s}$, $1 \mathrm{H},=\mathrm{CH}-), 6.49(\mathrm{~d}, J=16.1 \mathrm{~Hz}, 1 \mathrm{H},-\mathrm{CH}=), 6.90(\mathrm{~m}$, $1 \mathrm{H}, \mathrm{Ar}-\mathrm{H}), 6.85$ (brs, 1H, Ar-H), 7.06 (m, 1H, Ar-H), 7.96 (d, $J=16.1 \mathrm{~Hz}, 1 \mathrm{H},-\mathrm{CH}=), 1.00-3.00$ (22H, methyland methylene- of triterpenoid structure). ${ }^{13} \mathrm{C}-\mathrm{NMR}$ $\left(100 \mathrm{MHz} \mathrm{CDCl}_{3}\right)$ (ppm): 16.6, 17.0, 17.6, 18.9, 23.5, 23.9, 26.6, 26.7, 28.3, 28.6, 28.7, 31.1, 32.1, 32.9, 37.2, 37.9, 38.5, 39.0, 41.1, 43.4, 43.9, 45.7, 48.4, 55.3, $56.0\left(-\mathrm{OCH}_{3}\right), 56.3(-$ $\left.\mathrm{OCH}_{3}\right), 61.9,80.7,112.7,113.6,117.2,119.6,124.4,128.7$, 139.7, 153.0, 153.7, 167.3, 169.4, 181.0 (-COOH), 200.4 $(-\mathrm{C}=\mathrm{O}) . \mathrm{MS}(\mathrm{ESI}) \mathrm{m} / \mathrm{z}: 659[\mathrm{M}-\mathrm{H}]^{-}$, calcd. for $\mathrm{C}_{41} \mathrm{H}_{56} \mathrm{O}_{7}$ 660 .

(2,3,4-Trimethoxy) cinnamoyl-3 $\beta$-hydroxy-11-oxoolean12-en-30-oic acid (8a). White solid, yield: 66.7\%, m.p.: 315.1-317.9 ${ }^{\circ} \mathrm{C} .{ }^{1} \mathrm{H}-\mathrm{NMR}$ (400 $\mathrm{MHz}, \mathrm{CDCl}_{3}$ ) (ppm): $0.84,0.93,0.96,1.15,1.20,1.24,1.39$ (s, each, $3 \mathrm{H}, 7 \times-$ $\left.\mathrm{CH}_{3}\right), 3.87\left(\mathrm{~s}, 3 \mathrm{H},-\mathrm{OCH}_{3}\right), 3.89\left(\mathrm{~s}, 3 \mathrm{H},-\mathrm{OCH}_{3}\right), 3.92(\mathrm{~s}$, $\left.3 \mathrm{H},-\mathrm{OCH}_{3}\right), 4.66(\mathrm{~m}, 1 \mathrm{H}), 5.72(\mathrm{~s}, 1 \mathrm{H},=\mathrm{CH}-), 6.40(\mathrm{~d}$, $J=16.0 \mathrm{~Hz}, 1 \mathrm{H},-\mathrm{CH}=), 6.69(\mathrm{~d}, J=8.8 \mathrm{~Hz}, 1 \mathrm{H}, \mathrm{Ar}-\mathrm{H})$, $7.28(\mathrm{~d}, J=8.8 \mathrm{~Hz}, 1 \mathrm{H}, \mathrm{Ar}-\mathrm{H}), 7.88(\mathrm{~d}, J=16.0 \mathrm{~Hz}, 1 \mathrm{H}$, $-\mathrm{CH}=), 1.00-3.00(22 \mathrm{H}$, methyl- and methylene- of triterpenoid structure). ${ }^{13} \mathrm{C}-\mathrm{NMR}\left(100 \mathrm{MHz}, \mathrm{CDCl}_{3}\right)(\mathrm{ppm})$ : 16.6, 17.0, 17.6, 18.9, 23.5, 23.9, 26.6, 26.7, 28.3, 28.6, 28.7, 31.1, 32.0, 32.9, 37.2, 37.9, 38.5, 39.0, 41.1, 43.4, 44.0, 45.7, $48.4,55.3,56.2\left(-\mathrm{OCH}_{3}\right), 61.0\left(-\mathrm{OCH}_{3}\right), 61.6\left(-\mathrm{OCH}_{3}\right)$, 61.9, 80.6, 107.8, 117.8, 121.8, 123.2, 128.7, 139.4, 142.6, $153.4,155.6,167.5,169.4,181.5(-\mathrm{COOH}), 200.4(-\mathrm{C}=\mathrm{O})$. MS (ESI) m/z: $689[\mathrm{M}-\mathrm{H}]^{-}$, calcd. for $\mathrm{C}_{42} \mathrm{H}_{58} \mathrm{O}_{8} 690$.

(3,4,5-Trimethoxy) cinnamoyl-3 $\beta$-hydroxy-11-oxoolean12-en-30-oic acid (9a). White solid, yield: 55.2\%, m.p.: 315.3-317.7 ${ }^{\circ} \mathrm{C} .{ }^{1} \mathrm{H}-\mathrm{NMR}$ (400 $\mathrm{MHz}, \mathrm{CDCl}_{3}$ ) (ppm): $0.84,0.93,0.97,1.15,1.20,1.24,1.39$ (s, each, $3 \mathrm{H}, 7 \times-$ $\left.\mathrm{CH}_{3}\right), 3.88\left(\mathrm{~s}, 3 \mathrm{H},-\mathrm{OCH}_{3}\right), 3.89\left(\mathrm{~s}, 6 \mathrm{H}, 2 \times-\mathrm{OCH}_{3}\right)$, $4.68(\mathrm{~m}, 1 \mathrm{H}), 5.72(\mathrm{~s}, 1 \mathrm{H},=\mathrm{CH}-), 6.35(\mathrm{~d}, J=16.0 \mathrm{~Hz}$, $1 \mathrm{H},-\mathrm{CH}=), 6.75(\mathrm{~s}, 2 \mathrm{H}, \mathrm{Ar}-\mathrm{H}), 7.58(\mathrm{~d}, J=16.0 \mathrm{~Hz}, 1 \mathrm{H}$, $-\mathrm{CH}=), 1.00-3.00(22 \mathrm{H}$, methyl- and methylene- of triterpenoid structure). ${ }^{13} \mathrm{C}-\mathrm{NMR}\left(100 \mathrm{MHz}, \mathrm{CDCl}_{3}\right)(\mathrm{ppm})$ : 16.6, 17.0, 17.5, 18.8, 23.5, 23.9, 26.5, 26.6, 28.3, 28.6, 28.7, 31.1, 32.0, 32.9, 37.1, 37.9, 38.5, 39.0, 41.0, 43.4, 43.9, 45.6, $48.4,55.2,56.3\left(-\mathrm{OCH}_{3}\right), 61.1\left(-\mathrm{OCH}_{3}\right), 61.9,80.8,105.3$, $118.2,128.6,130.2,140.1,144.5,153.6,167.0,169.7,181.5$ $(-\mathrm{COOH}), 200.5(-\mathrm{C}=\mathrm{O})$. MS (ESI) m/z: $689[\mathrm{M}-\mathrm{H}]^{-}$, calcd. for $\mathrm{C}_{42} \mathrm{H}_{58} \mathrm{O}_{8} 690$.
General procedure for the preparation of glycyrrhetinic acidcinnamic acid hybrids $1 b-4 b$

Compounds 1a, 6a, 8a, 9a (2 mmol) were hydrogenated by $\mathrm{Pd} / \mathrm{C}(10 \% ; 50.0 \mathrm{mg})$ in $30 \mathrm{~mL}$ THF. The mixture was stirred at room temperature for $2 \mathrm{~h}$ and filtered to remove $\mathrm{Pd} / \mathrm{C}$. The filtrate was concentrated in vacuum.

Phenylpropanoyl-3 $\beta$-hydroxy-11-oxoolean-12-en30-oic acid (1b). White solid, yield: 94.0\%, m.p.: 313.6$316.5^{\circ} \mathrm{C} .{ }^{1} \mathrm{H}-\mathrm{NMR}\left(400 \mathrm{MHz}, \mathrm{CDCl}_{3}\right.$ ) (ppm): 0.80, 0.84, $0.84,1.13,1.15,1.23,1.27$ (s, each, $\left.3 \mathrm{H}, 7 \times-\mathrm{CH}_{3}\right), 2.64$ $\left(\mathrm{m}, 2 \mathrm{H},-\mathrm{CH}_{2}\right), 2.96\left(\mathrm{~m}, 2 \mathrm{H},-\mathrm{CH}_{2}\right), 4.52(\mathrm{~m}, 1 \mathrm{H}), 5.71(\mathrm{~s}$, $1 \mathrm{H},=\mathrm{CH}-)$, 7.17-7.22 (m, 3H, Ar-H), 7.27-7.30 (m, 2H, Ar-H), 1.00-3.00 (22H, methyl- and methylene- of triterpenoid structure). ${ }^{13} \mathrm{C}-\mathrm{NMR}\left(100 \mathrm{MHz}, \mathrm{CDCl}_{3}\right)(\mathrm{ppm})$ : 16.5, 16.7, 17.5, 18.8, 23.5, 23.7, 26.6, 26.6, 28.1, 28.6, 28.7, $31.1,31.3,32.0,32.9,36.4,37.1,37.9,38.2,38.9,41.0,43.4$, 43.9, 45.6, 48.4, 55.2, 61.9, 80.9, 126.4, 128.4, 128.6, 140.7, 169.6, 172.9, 181.7 (-COOH), $200.5(-\mathrm{C}=\mathrm{O}) . \mathrm{MS}(\mathrm{ESI})$ $\mathrm{m} / \mathrm{z}: 601[\mathrm{M}-\mathrm{H}]^{-}$, calcd. for $\mathrm{C}_{39} \mathrm{H}_{54} \mathrm{O}_{5} 602$.

(2,3-Dimethoxy) phenylpropanoyl-3 $\beta$-hydroxy-11-oxoolean-12-en-30-oic acid (2b). White solid, yield: 97.3\%, m.p.: $317.4-319.1{ }^{\circ} \mathrm{C}$. $1 \mathrm{H}-\mathrm{NMR}\left(400 \mathrm{MHz}, \mathrm{CDCl}_{3}\right)$ (ppm): 0.83, 0.83, 0.85, 1.13, 1.15, 1.23, 1.37 (s, each, $3 \mathrm{H}$, $\left.7 \times-\mathrm{CH}_{3}\right), 2.59-2.64\left(\mathrm{~m}, 2 \mathrm{H},-\mathrm{CH}_{2}\right), 2.93-2.98(\mathrm{~m}, 2 \mathrm{H}$, $\left.-\mathrm{CH}_{2}\right), 3.84\left(\mathrm{~s}, 3 \mathrm{H},-\mathrm{OCH}_{3}\right), 3.85\left(\mathrm{~s}, 3 \mathrm{H},-\mathrm{OCH}_{3}\right), 4.51$ $(\mathrm{m}, 1 \mathrm{H}), 5.71(\mathrm{~s}, 1 \mathrm{H},=\mathrm{CH}-), 6.80-6.77(\mathrm{~m}, 2 \mathrm{H}, \mathrm{Ar}-\mathrm{H})$, $6.97(\mathrm{t}, J=8.0 \mathrm{~Hz}, 1 \mathrm{H}, \mathrm{Ar}-\mathrm{H}), 1.00-3.00$ (22H, methyland methylene- of triterpenoid structure). ${ }^{13} \mathrm{C}-\mathrm{NMR}$ $\left(100 \mathrm{MHz}, \mathrm{CDCl}_{3}\right)$ (ppm): 16.5, 16.8, 17.5, 18.8, 23.5, 23.7, 25.7, 26.6, 26.6, 28.2, 28.6, 28.7, 31.1, 32.0, 32.9, 35.4, $37.1,37.9,38.2,39.0,41.0,43.4,43.9,45.6,48.4,55.2,55.9$ $\left(-\mathrm{OCH}_{3}\right), 60.7\left(-\mathrm{OCH}_{3}\right), 61.8,80.7,110.9,121.9,124.0$, $128.6,134.5,147.4,152.9,169.6,173.1,181.5(-\mathrm{COOH})$, $200.5(-\mathrm{C}=\mathrm{O})$. MS (ESI) m/z: $661\left[^{\mathrm{M}-\mathrm{H}}\right]^{-}$, calcd. for $\mathrm{C}_{41} \mathrm{H}_{58} \mathrm{O}_{7} 662$.

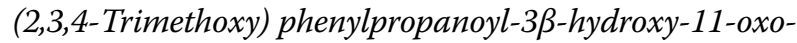
olean-12-en-30-oic acid (3b). White solid, yield: 95.5\%, m.p.: $316.3-319.1{ }^{\circ} \mathrm{C} .{ }^{1} \mathrm{H}-\mathrm{NMR}\left(400 \mathrm{MHz} \mathrm{CDCl}_{3}\right)$ (ppm): $0.81,0.83,0.84,1.12,1.15,1.22,1.37$ (s, each, 3H, 7×$\left.\mathrm{CH}_{3}\right), 2.58\left(\mathrm{t}, J=8.0 \mathrm{~Hz}, 2 \mathrm{H},-\mathrm{CH}_{2}\right), 2.88(\mathrm{t}, J=8.0 \mathrm{~Hz}$, $\left.2 \mathrm{H},-\mathrm{CH}_{2}\right), 3.83\left(\mathrm{~s}, 3 \mathrm{H},-\mathrm{OCH}_{3}\right), 3.85\left(\mathrm{~s}, 3 \mathrm{H},-\mathrm{OCH}_{3}\right)$, $3.89\left(\mathrm{~s}, 3 \mathrm{H},-\mathrm{OCH}_{3}\right), 4.50(\mathrm{~m}, 1 \mathrm{H}), 5.71(\mathrm{~s}, 1 \mathrm{H},=\mathrm{CH}-)$, $6.57(\mathrm{~d}, J=8.8 \mathrm{~Hz}, 1 \mathrm{H}, \mathrm{Ar}-\mathrm{H}), 6.83(\mathrm{~d}, J=8.8 \mathrm{~Hz}, 1 \mathrm{H}$, $\mathrm{Ar}-\mathrm{H}), 1.00-3.00$ (22H, methyl- and methylene- of triterpenoid structure). ${ }^{13} \mathrm{C}-\mathrm{NMR}\left(100 \mathrm{MHz}, \mathrm{CDCl}_{3}\right)$ (ppm): $16.5,16.8,17.5,18.8,23.5,23.7,25.7,26.5,26.6,28.1,28.6$, 28.7, 31.0, 32.0, 32.8, 35.6, 37.0, 37.8, 38.2, 38.9, 41.0, 43.3, $43.9,45.6,48.4,55.1,56.1\left(-\mathrm{OCH}_{3}\right), 60.8\left(-\mathrm{OCH}_{3}\right), 61.0(-$ $\left.\mathrm{OCH}_{3}\right), 61.8,80.6,107.2,123.9,126.6,128.5,142.4,152.0$, 152.5, 169.6, 173.2, 182.0 (-COOH), $200.5(-\mathrm{C}=\mathrm{O}) . \mathrm{MS}$ (ESI) m/z: $691[\mathrm{M}-\mathrm{H}]^{-}$, calcd. for $\mathrm{C}_{42} \mathrm{H}_{60} \mathrm{O}_{8} 692$. 
(3,4,5-Trimethoxy) phenylpropanoyl-3 $\beta$-hydroxy-11-oxoolean-12-en-30-oic acid (4b). White solid, yield: 95.5\%, m.p.: $315.1-319.7^{\circ} \mathrm{C} .{ }^{1} \mathrm{H}-\mathrm{NMR}\left(400 \mathrm{MHz}, \mathrm{CDCl}_{3}\right)$ (ppm): $0.79,0.83,0.85,1.12,1.15,1.23,1.37$ (s, each, $3 \mathrm{H}, 7 \times-$ $\left.\mathrm{CH}_{3}\right), 2.63\left(\mathrm{t}, J=8.0 \mathrm{~Hz}, 2 \mathrm{H},-\mathrm{CH}_{2}\right), 2.90(\mathrm{t}, J=8.0 \mathrm{~Hz}$, $\left.2 \mathrm{H},-\mathrm{CH}_{2}\right), 3.81\left(\mathrm{~s}, 3 \mathrm{H},-\mathrm{OCH}_{3}\right), 3.84(\mathrm{~s}, 6 \mathrm{H}, 2 \times-$ $\left.\mathrm{OCH}_{3}\right), 4.53(\mathrm{~m}, 1 \mathrm{H}), 5.71(\mathrm{~s}, 1 \mathrm{H},=\mathrm{CH}-), 6.42(\mathrm{~s}, 2 \mathrm{H}$, $\mathrm{Ar}-\mathrm{H}), 1.00-3.00(22 \mathrm{H}$, methyl- and methylene- of triterpenoid structure). ${ }^{13} \mathrm{C}-\mathrm{NMR}\left(100 \mathrm{MHz}, \mathrm{CDCl}_{3}\right)(\mathrm{ppm})$ : $16.5,16.9,17.5,18.8,23.5,23.8,26.5,26.6,28.1,28.6,28.7$, $31.1,31.6,32.0,32.8,36.5,37.1,37.9,38.2,38.9,41.0,43.4$, $43.9,45.6,48.4,55.2,56.2\left(-\mathrm{OCH}_{3}\right), 61.0\left(-\mathrm{OCH}_{3}\right), 61.8$, 80.9, 105.4, 128.6, 136.5, 136.6, 153.3, 169.6, 172.8, 181.6 (-COOH), $200.5(-\mathrm{C}=\mathrm{O}) . \mathrm{MS}(\mathrm{ESI}) \mathrm{m} / \mathrm{z}: 691[\mathrm{M}-\mathrm{H}]^{-}$, calcd. for $\mathrm{C}_{42} \mathrm{H}_{60} \mathrm{O}_{8} 692$.

\section{Bio-evaluation methods Cell culture}

HepG2 (human hepatocellular carcinoma), Hela (human cervical cancer), HT-29 (human colon carcinoma), MDCK (Madin-Darby canine kidney), H9C2 (rat myocardial cells) and HY926 were purchased from the Chinese Academy of Medical Sciences and Peking Union Medical College. All of these cell lines were maintained in RPMI-1640 (DMEM) supplemented with 10\% (v/v) fetal bovine serum (FBS) and 1\% (v/v) penicillin/streptomycin (Thermo Technologies, New York, NY, USA) under a humidified atmosphere containing $5 \% \mathrm{CO}_{2}$ at $37{ }^{\circ} \mathrm{C}$. To provide stock solutions which were used to prepare various concentrations of treatment media, GA and hybrids were added a volume of DMSO.

\section{Cytotoxicity evaluation}

The cytotoxicity of these compounds was evaluated on three human cancer cell lines (HepG2, HT-29, Hela) and three non-tumor cells lines (MDCK, HY926, H9C2) and MTT assay was performed to detect the cell proliferation. Simply, exponentially growing cells were cultured in 96-well plates $\left(3 \times 10^{3}\right.$ cells/well). And the plates were placed in a humidified atmosphere for $72 \mathrm{~h}$ at $37^{\circ} \mathrm{C}$ with $5 \% \mathrm{CO}_{2}$. After added MTT solution $(5 \mathrm{mg} / \mathrm{mL}) 20 \mu \mathrm{L}$ to each well, the plate was incubated for a further $4 \mathrm{~h}$. Then the cell supernatant was removed and $150 \mu \mathrm{L}$ DMSO was added. Finally, the absorbance was determined at wavelength of $490 \mathrm{~nm}$ with the ELISA. Wells without drugs were used to be blanks. The $\mathrm{IC}_{50}$ values were calculated using Logit-method. The following Eq. (1) was proposed to calculate the inhibitory rate of cell growth:

$$
\begin{aligned}
\% \text { inhibition }= & (1-\text { Sample group OD } \\
& / \text { Control group OD }) \times 100 \%
\end{aligned}
$$

\section{Acute toxicity}

Forty healthy Kunming mice (weight 18-22 g) of both sexes were purchased from Beijing Vital River Laboratory Animal Technology Company Limited (Beijing, China). The mice were divided into two groups matched the same weight and size, along with the standard in our previous studies [22]. In briefly, 20 mice were selected for blank control group, and the other 20 mice were for the treated group. All experiments followed the guidelines of "Regulation for the Administration of Affairs Concerning Experimental Animals" (State Council of China, 1988). All animals were placed in cages, fed with standard rodent chow and water ad libitum under a 12-h light-dark cycle. Before the experiments, the mice were deprived of food for $12 \mathrm{~h}$ but provided water freely. Then the treated group of both sexes were administered a single dose of $8 \mathbf{a}(0.3 \mathrm{~mL} / 10 \mathrm{~g})$ via gavage twice a day, which was prepared in advance in bean oil solution with the maximum suspended dose $(50 \mathrm{mg} / \mathrm{mL})$. The total administration of $8 \mathbf{a}$ was $3 \mathrm{~g} / \mathrm{kg}$ during $8 \mathrm{~h}$. And the blank control group were given bean oil by oral administration only. The mice's general behavior was continuously noted in the first hour, intermittently observed in the next $4 \mathrm{~h}$, and thereafter over a period of $24 \mathrm{~h}$. Observations of the signs for toxicity and deaths were last for 14 days. The mortality response and behavior of toxic effects of mice were recorded.

\section{Giemsa staining on Hela cells}

Hela cells were seeded in 12 -well plates $\left(5 \times 10^{3}\right.$ cells/ well), and then they were cultured for $24 \mathrm{~h}$ at $37^{\circ} \mathrm{C}$ with $5 \% \mathrm{CO}_{2}$. After that each group was added $8 \mathbf{a}$, making the final concentration of $0,5,10,20 \mu \mathrm{M}$ respectively. After $72 \mathrm{~h}$, the cell supernatant was removed and the cells were cleaned with PBS twice, then kept in PBS/ethanol (1:1) for $2 \mathrm{~min}$ and fixed with cold ethanol for $10 \mathrm{~min}$. After discarding ethanol, the cells were stained with Giemsa (Giemsa, Molecular Probes/Invitrogen Life Technologies, Carlsbad, CA, USA) stained for $5 \mathrm{~min}$ and washed with water. In the end, the cells were observed and photographed under inverted phase-contrast microscope at a magnification of $200 \times$.

\section{H33342 staining on Hela cells}

H33342 staining was used to confirm whether the characteristic nuclear changes were associated with $8 \mathrm{a}$ in this assay. Hela cells were cultured in 12 -well plates $\left(5 \times 10^{4}\right.$ cells/well), which were placed in a humidified atmosphere for $24 \mathrm{~h}$ at $37{ }^{\circ} \mathrm{C}$ with $5 \% \mathrm{CO}_{2}$. And then each group was added 8a, making the final concentration of 0 , $5,10,20 \mu \mathrm{M}$ respectively. After $72 \mathrm{~h}$, cell culture medium was discarded and the cells were washed twice with 
PBS. H33342 staining was then performed for $2 \mathrm{~min}$ and washed with water. In the end, the cells were observed and photographed under inverted phase-contrast microscope at a magnification of $200 \times$.

\section{Annexin V-FITC/propidium iodide (PI) assay}

Hela cells were seeded in 12-well plates $\left(5 \times 10^{4}\right.$ cells/ well), which were placed in a humidified atmosphere for $24 \mathrm{~h}$ at $37{ }^{\circ} \mathrm{C}$ with $5 \% \mathrm{CO}_{2}$. After treated with different concentrations of $\mathbf{8 a}(5,10,20 \mu \mathrm{M})$ for $72 \mathrm{~h}$, all cells were collected respectively with the right amount of trypsin (without EDTA) digestion. After added $1 \mathrm{~mL}$ cold PBS, the cells were gently suspended and centrifuged at $1000 \mathrm{rpm}$ for $5 \mathrm{~min}$. The harvested cells were suspended in $200 \mu \mathrm{L}$ binding buffer which contained $10 \mu \mathrm{L}$ Annexin V-FITC and PI. After avoided light reaction for $15 \mathrm{~min}$, the cells were analyzed with a flow cytometry (BD, USA).

\section{Caspase-3 assay}

Hela cells were seeded in dishes at a density of $5 \times 10^{5}$ cell per dish and the dishes were kept at $37{ }^{\circ} \mathrm{C}$ with $5 \%$ $\mathrm{CO}_{2}$ for $24 \mathrm{~h}$. On the next day, various concentration of $8 \mathrm{a}(0,5,10,20 \mu \mathrm{M})$ were added to the cells and cultured for $48 \mathrm{~h}$. Pre-cooled PBS were added twice to wash the cells. After removal of the medium, ice-cold cell lysis buffer was added, and the cells were further incubated in an ice bath for $15 \mathrm{~min}$, which contribute to the protein acquisition. The caspase-3 activity kit (Beyotime Institute of Biotechnology, Beijing, China) was used to determine the activity of caspase-3. A total of $50 \mu \mathrm{L}$ cell lysates, $40 \mu \mathrm{L}$ reaction buffer and $10 \mu \mathrm{L}$ caspase- 3 substrate (Ac-DEVDpNA) (2 mM) were added to 96-well plates. After $30 \mathrm{~min}$ of incubation, absorbance was measured at $405 \mathrm{~nm}$, and samples were quantified with ELISA.

\section{Authors' contributions}

MY, PW and WG designed the study; WW, MY and WG performed experiments; WG and MY collected data; FC, BX, XJ, CZ, YH, HX and YZ analysed data; PW, WG and MY wrote the paper. HL was the principle investigator of the project and provided the research funding. All authors read and approved the final manuscript.

\section{Author details}

${ }^{1}$ School of Chinese Pharmacy, Beijing University of Chinese Medicine, No.6 Wangjing Middle Ring South Road, Beijing, Chaoyang District, China. ${ }^{2}$ Department of Pathology, Beijing University of Chinese Medicine, No.11 North Third Ring Road, Beijing, Chaoyang District, China.

\section{Acknowledgements}

This study was financially supported by the National Natural Science Foundation of China (No. 81173519), the Innovation Team Project Foundation of Beijing University of Chinese Medicine (Lead Compound Discovering and Developing Innovation Team Project Foundation, no. 2011-CXTD-15) and the Program of Student Innovation Training and the Project of Beijing (No. BJGJ1528)

\section{Competing interests}

The authors declare that they have no competing interests.
Received: 15 April 2016 Accepted: 23 November 2016

Published online: 01 December 2016

\section{References}

1. van Ginkel PR, Yan MB, Bhattacharya S, Polans AS, Kenealey JD (2015) Natural products induce a $G$ protein-mediated calcium pathway activating p53 in cancer cells. Toxicol Appl Pharmacol 288:453-462

2. Wenzel SC, Hoffmann H, Zhang J, Debussche L, Haag-Richter S, Kurz M, Nardi F, Lukat P, Kochems I, Tietgen H, Schummer D, Nicolas JP, Calvet L, Czepczor V, Vrignaud P, Mühlenweg A, Pelzer S, Müller R, Brönstrup M (2015) Production of the bengamide class of marine natural products in myxobacteria: biosynthesis and structure-activity relationships. Angew Chem Int Ed 54:15560-15564

3. Chakravarti B, Maurya R, Siddiqui JA, Bid HK, Rajendran SM, Yadav PP, Konwar R (2012) In vitro anti-breast cancer activity of ethanolic extract of Wrightia tomentosa: role of pro-apoptotic effects of oleanolic acid and urosolic acid. J Ethnopharmacol 142:72-79

4. Shanmugam MK, Dai X, Kumar AP, Tan BK, Sethi G, Bishayee A (2013) Ursolic acid in cancer prevention and treatment: molecular targets, pharmacokinetics and clinical studies. Biochem Pharmacol 85:1579-1587

5. Lallemand B, Gelbcke M, Dubois J, Prévost M, Jabin I, Kiss R (2011) Structure-activity relationship analyses of glycyrrhetinic acid derivatives as anticancer agents. Mini Rev Med Chem 11:881-887

6. Yang S, Liang N, Li H, Xue W, Hu D, Jin L, Zhao Q, Yang S (2012) Design, synthesis and biological evaluation of novel betulinic acid derivatives. Chem Cent J 6:141

7. Liang D, Zhou Q, Zhang J, Gong W, Xu C, Li B, Wang Y, Li J (2012) A novel chenodeoxycholic acid-verticinone ester induces apoptosis and cell cycle arrest in HepG2 cells. Steroids 77:1381-1390

8. Li G, Xu X, Xu K, Chu F, Song J, Zhou S, Xu B, Gong Y, Zhang H, Zhang Y, Wang P, Lei H (2015) Ligustrazinyl amides: a novel class of ligustrazinephenolic acid derivatives with neuroprotective effects. Chem Cent J 9:9

9. Xu B, Gong Y, Xu X, Zhang C, Zhang Y, Chu F, Liu H, Wang P, Lei H (2015) Synthesis and protective effect of new ligustrazine derivatives against $\mathrm{CoCl}_{2}$-induced neurotoxicity in differentiated PC12 cells. Part 2. MedChemComm 6:806-809

10. Zhang C, Yan W, Li B, Xu B, Gong Y, Chu F, Zhang Y, Yao Q, Wang P, Lei H (2015) A new ligustrazine derivative-selective cytotoxicity by suppression of NF-KB/p65 and COX-2 expression on human hepatoma cells. Part 3. Int J Mol Sci 16:16401-16413

11. Chu F, Xu X, Li G, Gu S, Xu K, Gong Y, Xu B, Wang M, Zhang H, Zhang Y, Wang P, Lei $H$ (2014) Amino acid derivatives of ligustrazine-oleanolic acid as new cytotoxic agents. Molecules 19:18215-18231

12. Xu B, Chu F, Zhang Y, Wang X, Li Q, Liu W, Xu X, Xing Y, Chen J, Wang P, Lei $H$ (2015) A series of new ligustrazine-triterpenes derivatives as antitumor agents: design, synthesis, and biological evaluation. Int J Mol Sci 16:21035-21055

13. Li Y, Feng L, Song ZF, Li HB, Huai QY (2016) Synthesis and anticancer activities of glycyrrhetinic acid derivatives. Molecules 21:199

14. Schwarz S, Siewert B, Xavier NM, Jesus AR, Rauter AP, Csuk R (2014) A "natural" approach: synthesis and cytoxicity of monodesmosidic glycyrrhetinic acid glycosides. Eur J Med Chem 72:78-83

15. Csuk R, Schwarz S, Kluge R, Ströhl D (2010) Synthesis and biological activity of some antitumor active derivatives from glycyrrhetinic acid. Eur J Med Chem 45:5718-5723

16. Csuk R (2014) Recent developments in the synthesis of antitumor-active glycyrrhetinic acid derivatives. Mini Rev Org Chem 11:253-261

17. Sharma R, Guru SK, Jain SK, Pathania AS, Vishwakarma RA, Bhushan S, Bharate SB (2015) 3-(2,6-Dichloro-benzyloxy)-11-oxo-olean-12-ene-29-oic acid, a semisynthetic derivative of glycyrrhetic acid: synthesis, antiproliferative, apoptotic and anti-angiogenesis activity. MedChemComm 6:564-575

18. De P, Baltas M, Bedos-Belval F (2011) Cinnamic acid derivatives as anticancer agents - a review. Curr Med Chem 18:1672-1703

19. Zhang WM, Xing M, Zhao TT, Ren YJ, Yang XH, Yang YS, Zhu HL (2014) Synthesis, molecular modeling and biological evaluation of cinnamic acid derivatives with pyrazole moieties as novel anticancer agents. RSC Adv 4:37197-37207 
20. Su P, Shi Y, Wang J, Shen X, Zhang J (2015) Anticancer agents derived from natural cinnamic acids. Anticancer Agents Med Chem 15:980-987

21. Xu C, Deng T, Fan M, Lv W, Liu J, Yu B (2016) Synthesis and in vitro antitumor evaluation of dihydroartemisinin-cinnamic acid ester derivatives. Eur J Med Chem 107:192-203
22. Wang P, She G, Yang Y, Li Q, Zhang H, Liu J, Cao Y, Xu X, Lei H (2012) Synthesis and biological evaluation of new ligustrazine derivatives as anti-tumor agents. Molecules 17:4972-4985

\section{Submit your manuscript to a SpringerOpen ${ }^{\odot}$ journal and benefit from:}

- Convenient online submission

\section{- Rigorous peer review}

- Immediate publication on acceptance

- Open access: articles freely available online

- High visibility within the field

- Retaining the copyright to your article 